\title{
ARTICLES
}

\section{The Internet as a Medium for Education and Educational Research}

by Marcos SIlva and Glonn F. Cartwright

\begin{abstract}
This paper examines the advent of the Internet and its impact on K-12 education and librarianship. It discusses the use of the Internet as a resource for teaching and research and as a virtual classroom and laboratory. In addition, the reasons justifying investment in national supernetworks such as the American National Research and Education Network (NREN) and the Canadian Network for the Advancement of Research, Industry, and Education (CANARIE) are outlined. Finally, the implications for education and librarianship concerning the establishment of these supernetworks are explored.
\end{abstract}

The advent of the Internet, a vast worldwide network of computer networks, has had a significant impact on educational research and librarianship. Indeed, the myriad of available services, resources, and information on the Internet in support of $\mathrm{K}$-university research is impressive. But the Internet may be also viewed as a virtual classroom and laboratory: it can serve and function as a viable medium for educational research as well as a conduit for education.

At present, there exists a wealth of descriptive works detailing the resources available on the Internet (Kehoe, 1993; Krol, 1992; Tennant, 1992; Giguère, 1992). There are also many catalogs, most retrievable via the Internet, available to educators indicating the location of electronic resources (Barron, 1992; Drew, 1992; ERIC Clearinghouse on Information Resources 1992; SURAnet 1993).

Research has also centered on the creation of electronic resource discovery tools to help users of the INTERNET locate items of interest. Deutsch (1992) succinctly outlined many of the issues concerning the problem of identifying and locating resources in a distributed environment. The research in this area is of particular importance given the Internet's size of over 20 million users and its growth of approximately $10 \%$ a month (Lottor, 1992).

The evolution and future of the Internet has also attracted attention. Hart, Robert, and Bar (1992) have written one of the best introductions to the history and evolution of the Internet. Their inclusion of issues that directly pertain to education and educational psychology makes the work invaluable to educators.
Research, however, that explicitly examines the impact of the Internet on education is lacking. Again, most studies on the Internet and education have been of the descriptive variety (Silva \& Cartwright, in press; Howse, 1991). Paulsen's (1991) excellent annotated bibliography on education and computer mediated communication does offer some direction to the researcher. Still, few studies are available that offer formal analyses of the interaction and evolution of the Internet and education.

The purpose of this paper is to examine some of the issues concerning educators which arise from the advent of the Internet. It will describe how the Internet is being used to support research and education and how it can be utilized as a virtual classroom for provision of education. Also discussed are projects such as the National Research and Education Network and the Canadian Network for the Advancement of Research, Industry and Education.

The Internet as a Resource in Support of Educational Research Online Library Catalogues and Databases

At present, the Internet offers a wealth of resources in support of educational research. Perhaps the most utilized of these resources is the ability to search remote, online library catalogues and databases from a local computer via the Internet protocol "telnet." Researchers are able to access some of the most extensive library collections in the world such as Harvard University, Oxford, and the University of California. In this manner, it is possible to keep abreast of new publications, verify 
obscure materials, and discover which sites have materials of particular interest.

Using telnet, educators can also search databases that hold materials which are pertinent to education. ERIC, for instance, possibly the world's most extensive database on education, can be accessed without restriction throughout a number of sites in North America: Auburn University offers the complete holdings of the database (1966-to date) while the University of North Carolina offers a searchable, full-text file of Eric Digests.

Some research sites have databases that index local or unique collections. Dartmouth University allows free access to the Project Cork collection whose holdings include materials on alcoholism and substance abuse. Princeton University gives access to Early American Imprints, a database containing over 36,000 bibliographic records of materials published before 1800 in what is now the United States. These resources may be of value to researchers and students and merit evaluation by librarians.

\section{Electronic Publishing}

Another development of interest to educators and librarians is the advent of electronic publishing, a phenomenon whose growth has closely paralleled the growth of the Intemet. At this writing there are 36 electronic journals in publication of which 27 are peer reviewed (Strangelove, 1993). This figure does not include electronic newsletters and newspapers. Moreover, this represents a $33 \%$ increase in the total number of existing electronic journals during the first two months of 1993 (Stangelove, 1993).

What makes this phenomenon of particular value to researchers is that these journals, once located, can be retrieved in full text. The most common way to retrieve a particular article is through the use of an Internet protocol called FTP (File Transfer Protocol). Basically, FTP allows a user to send or retrieve binary or text files from a remote computer to a host computer.

However, a far easier method is through the use of discovery resource tools such as gophers, archie, Wide Area Information Servers (WAIS), and World Wide Web. Simply put, these tools index resources found on the Internet and give the user a gateway to the needed item. Locating and retrieving materials in a distributed environment such as the Internet becomes more intuitive and less complicated. Of these resource discovery tools, gophers have become one of the most commonly used.

A gopher is a system that allows a user to browse or search a hierarchy of information in a distributed environment such as the Internet. This concept is based on three separate parts: clients, servers and a communication protocol. The client can be thought of as the user interface and the server as the software that does the indexing and retrieval of information. Clients and servers function independently from one another. The communication protocol is the software which allows for seamless communication between separate clients and servers.

For example, although articles from the "EDUCOM Review" are available via FTP, EDUCOM has created a gopher system that gives the researcher access to the full text of the journal. Once the needed article is found, the text can be read online or retrieved and printed. Again, the use of a gopher system, or any other resource discovery tool, requires far less computer and telecommunications knowledge than normally required when navigating the Internet directly via an operating system. Franks (1993), in an excellent summary of what constitutes an electronic journal, summarizes the advantages of a gopher system: “A simpler, easy-to-use user interface, on-line browsing of abstracts or full-text, keyword searching of abstracts or full text, immediate downloading of desired articles."

In summary, the reasons to publish a journal in electronic format include: increased readership, research is published expeditiously, increased accessibility, multi-media possibilities, and immediate or prompt feedback concerning research.

\section{Electronic Books}

The advent of Internet-accessible books has also shown exceptional growth. Project Gutenberg, under the direction of Michael S. Hart, has the stated goal of giving away one trillion "etexts" by December 31, 2001. Other resources include virtual libraries accessible via the Internet. Dartmouth's Shakespeare Project, for example, has loaded the full text of all of Shakespeare's sonnets and thirty-three of his plays. Shakespearean students and scholars with access to the Internet, therefore, have access to a powerful and easy-to-use electronic concordance.

The impact of electronic books has been the emergence of new research methodologies and disciplines. Large scale textual analysis was virtually non-existent a few years ago. Electronic concordance generation along with electronic etymological studies are also a new scholarly activities. A student interested in Melville's use of color in "Moby Dick" can search effortlessly the entire novel for instances of the adjective white in a matter of seconds.

\section{Electronic Discussion Groups}

The ability to communicate with anyone on the Internet is perhaps one of the services most widely exploited. The dissemination of information using electronic mail is rapid, seamless and transparent. However, the fragmentation of knowledge, as a result of the exponential growth of information arising from electronic disseminat: $s n$, remains a very real possibility. To meet this challenge, use of moderated electronic discussion groups as a means to better organize and optimize the flow of information among the scholarly and educational community has become commonplace.

For instance, a recent message posted on the Public-Access Computer Systems Forum electronic discussion list (PACSL@UHUPVM1) announced that the Library of Congress Information System (LOCIS) is accessible via the Internet (Stork, 1993). Given that thousands of individuals subscribe to PACS-L, the impact of this non-traditional method of information sharing should not be underestimated. 
Electronic discussion groups exist for almost any discipline and the choices available to educators and librarians are many. A quick search of Kovac's Directory of Scholarly Electronic Conferences retrieved over 30 library-related discussion groups and over 40 education related discussion groups. This does not include many other groups which happen to discuss library or education related issues. An example is the Interpersonal and Computing Technology list which is devoted to examining issues like computer mediated communication, human-machine interaction, etc. At present, the list has carried a fascinating discussion on whether or not writing skills are improved by the use of computers.

An example of the use of electronic mail is the service offered by Eric Clearinghouse on Information Resources called AskERIC. Essentially, AskERIC provides via electronic mail, a question-answering, help, and referral service for K-12 educators, researchers, and school librarians and administrators. Any questions concerning any aspect of K-12 education can be sent to AskERIC; a reply is usually received with 24 to 48 hours. What makes this resource so specially attractive is that it is absolutely free; the user incurs no charges.

The challenge for educators and librarians is to effectively incorporate this resource in their respective professions. It could be argued that subscription to a discussion group is rapidly becoming an essential part of a professional's administrative, educational, and academic responsibility. It could be further argued that librarians and educators now have the additional responsibility of introducing and recommending electronic discussion groups to students and colleagues.

\section{Issues for Educators and Librarians}

Gregorian, Hawkins, and Taylor (1992), participants in the Higher Education Information Resources Alliance, a cooperative project among EDUCOM, CAUSE and the Association of Research Libraries, claim that "the greatest challenge facing modern society and civilization is how to cope with information and transform it into knowledge" (p. 5). Given the "accelerating electronic torrent from thousands of databases around the world" (p.5), educators and librarians must confront the "disruption and stresses of information as they are found on our own campuses" (p. 5). Without argument, this challenge is also faced by $\mathrm{K}-12$ educators and librarians.

The task for educators, therefore, becomes how to exploit these new learning opportunities and integrate them with traditional teaching activities. Educational researchers must remain alert to the implications that electronic resources have for education and learning. Librarians must offer guidance and support to those educators, researchers, and students who are attempting to navigate through the Internet. They must be able to filter, distill, organize, and rank information so that it may be effectively transformed into knowledge.
The Internet as a Medium for Education

Studies concerning the use of the Internet as a medium for education and research have been recent. EDUCOM has been a leader in the promotion of the Internet as a virtual classroom and has consistently offered a forum for researchers wishing to share their work. Still, most of the published work is of a descriptive nature; rigorous formal studies are lacking.

The lack of formal studies has not, however, impeded the use of the Internet as a virtual classroom or laboratory. Indeed, the number of ongoing research and education projects is large. Surprisingly, use of the Internet for virtual studies has not been limited to universities; K-12 educators, librarians, and students are active participants (Clements, 1992a, 1992b).

\section{The Internet as a Virtual Classroom}

One of the more innovative uses of the Internet occurred this fall with the creation of "Navigating the Internet: An Interactive Workshop," created by Richard J. Smith at the University of Southwestern Louisiana in collaboration with Jim Gerland of the University of Buffalo. The workshop was a first attempt to teach librarians and others Internet protocols. Over 12,000 registered participants "attended" the workshop which lasted for more than seven weeks. Of note is that the workshop was conductedentirely over the Internet.

In his synthesis and evaluation of the workshop, Smith (1993) notes that many participants commented that the workshop seemed more akin to a full credit course. Smith is investigating the possibility of offering the seminar as part of the curriculum in a school of library science. In addition, many requests for another session have been received. Finally, plans for a $\mathrm{K}-12$ workshop are under way.

Some interesting $\mathrm{K}-12$ projects exploiting the Internet as a virtual classroom include North Dakota's SENDIT, a BBS-type networking that gives students and educators a gateway to the Internet. By late December 1992, the project participants included 769 teachers, 1,521 students, and 84 administrators (Sackman, 1993).

Applications of the project include: e-mail, electronic discussiongroups, a forum on new legislative bills for government and history classes, and inter-library loans. Perhaps the most innovative application of SENDIT is the Electronic Classroom where "SENDIT users are able to access the CNN Newsroom guide, Newsweek guide/quiz, discussion groups, and historical documents" (Sackman, 1993, p.8).

Another fascinating K-12 project is KIDSLINK, an electronic forum where children communicate via the Internet. Originally conceived by Odd de Presno, author and educator, KIDSLINK now links many thousands of children among 46 different countries. KIDSLINK in tum is composed of several other forums. KIDS-93, a grassroots project, attempts to join children worldwide in a dialog of views on the desired future of the planet. In contrast, KIDSCAFE allows children to "talk" about whatever they like. Other KIDSLINK forums have essentially the same objective: to give children a means to reach out across their cultures and boundaries. 
The Internet as a virtual classroom has also engendered a number of projects stressing $\mathrm{K}$-university cooperation. The aim is to give $\mathrm{K}-12$ educators and students access to information and resources normally unavailable (Clements, 1992a) to their community. Clements (1992a) sees this evolving partnership as a means of optimizing scarce resources and thereby contributing to the revitalization of the public school system.

Examples include Virginia Polytechnic Institute and State University's efforts to give K-12 schools in Virginia access to the Internet. The El Paso Community College has organized a program where $\mathrm{K}-12$ educators learn how to utilize resources found on the Internet. Perhaps the most extensive project promoting greater resource sharing between academic centres and $\mathrm{K}-12$ schools is the Texas Education Network (TENET), which as of April 1992, had over 9,000 participants. TENET is growing at the phenomenal rate of 1,000 new participants a month (Clements, 1992b). And finally, The California Museum of Photography at the University of California, Riverside is establishing the development of virtual art exhibitions directed at K-12 schools. The Project aims to place over 5000 photographs, at screen resolution, on the Internet (Cisler, 1993).

\section{The Internet as a Virtual Laboratory}

The Internet must be understood as both a resource in support of research, and as a virtual laboratory for research. A number of projects requiring close collaboration and communication among researchers have been implemented on the Internet. Again, formal rigorous studies examining the results of these projects are rare.

Koch, in her study of the impact of networks upon scientific research, concluded that "electronic networks are improving scientists' productivity by making their communication more efficient" (1991, p. 79). Nevertheless, she notes that several problems remain: information overload, quality control, and lack of a categorization of resources.

Still, as is often the case, the lack of research has not impeded evolution of the phenomenon. Note, for instance, the invitation to join an ongoing research project on the use of electronic mail discussion lists placed on the Internet (Rafaeli \& Sudweeks, 1993). This international project depends on the Internet for communication, exchange of data and findings, and data analysis.

Interest concerning use of the Internet as a virtual laboratory is growing. For example, the Innovative Research Trends in the Human Sciences Conference, University of Alberta, November 27-28, 1992, emphasized the use of new communications technologies. The 1992 meeting of the Computers and Multimedia Group of the American Political Science Association devoted a substantial time to discussing the implications of telecommunications on research and education. And finally, the International Conference on TeleTeaching '93, which is normally concerned with uses of telecommunications for teaching, will hold its preconference through electronic mail via the Internet!
Future Issues

\section{The National Research and Education Network (NREN)}

Plans to invest in the expansion of existing national networks have been implemented in several countries. In the United States the project was signed into law by President George Bush on December 9, 1991. The Act, called the High-Performance Computing Act of 1991, gives the impetus for the establishment of a supernetwork linking research centres, universities, and industry and government. This effort has been named the National Research and Education Network.

Indeed, the NREN is perceived as being essential to the United States' economic well-being and crucial to future research. It is for this reason that the stated purpose of the Act is to "Help ensure the continued leadership of the United States in high-performance computing and its applications..." (U.S. Congress, Senate, High-Performance Computing Act of 1991, 102nd Cong., 1st sess., S. 272, Sec. 3).

However, of special interest to $\mathrm{K}$-university educators and librarians is the call in the Act to "Invest in basic research and education, and promote the inclusion of high-performance computing into educational institutions at all levels" (U.S. Congress, Senate, High-Performance Computing Act of 1991, 102nd Cong., 1st sess., S. 272, Sec. 3, (1), (H)). In fact, the Act stipulates that the National Science foundation shall have the responsibility of linking colleges, universities, and libraries that cannotconnect to the Network with the assistance of the private sector (Sec 201, (2)).

Efforts not to exclude K-12 educators and libraries from the new network are under way. Vice President Gore, while a Senator, also sponsored the Information Infrastructure and Technology Act of 1992 (Gore, 1992). Although the bill died with the adjournment of Congress, Gore has stated his intent to work with Congress to introduce a similar bill.

Essentially, the bill attempted to ensure that the technology developed by and available on the NREN would be accessible by $\mathrm{K}-12$ educators and students, public libraries, health care, and small businesses. Indicative of the realization that $\mathrm{K}-12$ schools and libraries must partake in the benefits of the NREN is the decision of the Department of Education to target the nation's public libraries as access points to its network, SMARTLINE (United States. Office of Science and Technology Policy, 1992, p. 25).

\section{The CanadianNetwork for the Advancement of Research, Indus- try and Education}

In Canada, a similar project is called the Canadian Network for the Advancement of Research, Industry, and Education (CANARIE). Similar to NREN, CANARIE policy makers see libraries and schools as one of its primary beneficiaries. Indeed, the Canadian educational community from all constituencies is explicitly recognized being an integral part ofits user community (CANARIE Marketing Plan Working Group, p.9). In addition, all sectors of the information and library community are expected 
to participate and share in the resources of CANARIE.

The reasons for the establishment of CANARIE are identical to those of the NREN: "To support Canada's economic growth and enhance its international competitiveness through the promotion, development, and use of high-speed communications network products and services" (CANARIE Marketing Plan Working Group, p. 8). And similar to the NREN, one of the major benefits of CANARIE will be "the linkage of the educational community from public school through college to university for purposes of education and information exchange" (CANARIE Business Plan Working Group, p. 7).

\section{Conclusion}

The Internet must be understood as comprising more than a mere information network: it is a virtual classroom, library, and laboratory, whose potential user and student population is almost without limits. In addition, the NREN and CANARIE and other similar projects will bring new technologies like video conferencing and virtual reality to the reach of the most rural schools or libraries. The implications for $\mathrm{K}-12$ education and librarianship are significant.

First and foremost, educators must take a leadership role concerning the integration of the Internet with traditional classroom teaching and activities. This will ensure that children have the opportunity to exploit the myriad resources on the network while linking $\mathrm{K}-12$ educators to a very real community of other researchers and scholars.

Second, the advent of the Internet requires the planning of new curricula and activities. It is not surprising, therefore, to find a blossoming of cooperative projects between $\mathrm{K}-12$ educators and universities. K-12 educators need access to the resources and expertise found in the university community, while scholars see an opportunity to participate in the revitalization of the nation's schools and curricula.

Librarians, in turn, must adjust to this new paradigm by offering the educational community support concerning categorization and use of resources on the Internet. In this sense, librarians become far more active in the teaching and instruction role; they must guide and instruct users, both students and teachers, in the navigation of the Internet.

This implies a radical shift in librarianship: the librarian as an analyzer as well as an accesser of data. This shift is caused by the lack of information filters available on the Internet; the amount of information is enormous. In addition, the librarian will take a more active teaching role, possibly in cooperation with a teacher.

This evolving partnership among universities, K-12schools, and libraries offers the teaching and library profession the opportunity for renewal and innovation. Our professions have been given the tools, it is up to us to make the most productive use of them.

\section{References}

Barron, B. (1992) UNT's accessing on-line bibliographic databases. Danton, TX: University of North Texas. [Computer file, available via FTP, FTP.UNT.EDU, /library/libraries.txt]

Canadian Network for the Advancement of Research, Industry and Education, Business Plan Working Group. (1992). Report of the Business Plan Working Group. (N.p.).

Canadian Network for the Advancement of Research, Industry and Education, Marketing Plan Working Group.(1992). Report of the Marketing Plan Working Group. Draft 2.0. (N.p.).

Cisler, S. (1993). Apple library of Tomorrow Awards for 1993: Community Networks. Electronic message posted to Public-Access ComputerSystemsForum.PACS-L@UHUPVM1.BITNET, March 3, 1993.

Clements, J. (1992a). Network-Based Collaborations: How universities can support K-12 reform efforts. EDUCOM Review, 27, 9-12.

Clements, J. (1992b). Surveying K-12 and postsecondary school networking partnerships. EDUCOM Review, 27, 44-46.

Deutsch, P. (1992). Resource discovery in an Internet environment. Unpublished master's thesis, McGill University, Montreal, Canada.

Drew, W. (1992). Not just cows: A guide to Internet/Bitnet re sources in agriculture and related sciences. Morrisville, NY: Morrisville College of Agriculture and Technology, State University of New York. [Computer file, available via FTP, FIP.SURA.NET,/pub/ nic/agricultural.list]

Eric Clearinghouse on Information Resources. (1992). Internetaccess points to ERIC (ERIC Networker 4.0). Syracuse, NY: ERIC Clearinghouse on Information Resources. [Computer file, available via FTP, FTP.SURA.NET, /pub/nic/ERIC.sites].

Franks, J. (1993). What is an Electronic Journal? Electronic message posted to Public-Access Computer Systems Forum Discussion list. PACS-L@UHUPVM1.BITNET, January 23, 1993.

Giguère, M. (1992). An introduction to services accessible on the Internet. Education Libraries, 16, 5-9.

Gore, A. (1992). The Information Infrastructure and Technology Act. EDUCOM Review, 27(5), 26-29.

Gregorian, V., Hawkins, B. L., \& Taylor, M.(1992). Integrating information technologies: A research university perspective. Cause Effect, 5-12.

Hart, J. A., Reed, R. R., \& Bar, F. (1992). The building of the Internet: Implications for the future of broadband networks. Telecommunications Policy, 16, 666-689.

Howse, W. J. (1991). Internet-The discoveries of a distance educator. DEOSNEWS, 1(21). [Electronic journal].

Kehoe, B.P. (1993). Zen and the art of the Internet: $A$ beginner's guide. (2nd ed.). Englewood Cliffs, NJ: PTR Prentice Hall.

Koch, S. (1991). Electronic networks and science. In C. R. McClure, A. P. Bishop, P. Doty, \& H. Rosenbaum (Authors), The National Research and Education Network (NREN): Research and Policy Perspectives (pp. 69-85). Norwood, NJ: Ablex.

Krol, E. (1992). The whole Internet: User's guide \& catalog. Sebastopol, CA: O'Reilly \& Associates.

Lottor, M. (1992). Internet Growth (1981-1991) (RFC 1296). Menlo Park, CA: SRI International. [Computer file, available via FTP, NIS.NSF.NET, /documents/RFC/RFC1296.txt].

Paulsen, M. F. (1991). Computer-mediated communication and distance education around the world. DEOSNEWS, 1(10). [Electronic journal].

Rafaeli, S., \& Sudweeks, F. (1993). Invitation to join research project. Electronic message posted to Public-Access Computer Systems Forum Discussion list. PACS-L@UHUPVM1.BITNET, J a nu ary $19,1993$. 
Sackman, G. (1993). North Dakota K-12 students and educators network with SENDIT. Internet World, 4(4), 8-9.

Silva, M., \& Cartwright, G. F. (in press). The design and implementation of Internet seminars for library users and staff at McGill University. Education for Information.

Smith, R. (1993). Report on Navigating the Internet. Electronic message posted to Public-Access Computer Systems Forum Discussion list. PACS-L@UHUPVM1.BITNET, January 12, 1993.

Stork, Judy L. (1993). LC Files Now on Internet. Electronic message posted to Public-Access Computer Systems Forum Discussion list. PACS-L@UHUPVM1.BITNET, May 5, 1993.

Strangelove, M. (1993). Reflections on Developments Draft RFC. Electronic message posted to Publishing E-Journals: Publishing, Archiving, and Access Discussion list.VPIEJ-L@VTM1.BITNET, February 15, 1993.

Tennant, R. (1992). Internet basics (ERIC Digest EDO-IR-92-7). Syracuse, NY: ERIC Clearinghouse on Information Resources.

United States. Office of Science and Technology Policy. (1992). The National Research andEducation NetworkProgram: A Report to Congress. [Washington, DC: GPO].

United States. Congress. Senate. High-Performance Computing Act of 1991. 102nd Congress, 1st session, S. 272. [Computer file, available viaFIP,NIC.MERIT.EDU, nren/hpca.1991/nrenbill.txt] 